\title{
Comparison of Retracking Algorithms Using Airborne Radar and Laser Altimeter Measurements of the Greenland Ice Sheet
}

\author{
Ellen J. Ferraro, Member, IEEE, and Calvin T. Swift, Fellow, IEEE
}

\begin{abstract}
This paper compares four continental ice sheet radar altimeter retracking algorithms using airborne radar and laser altimeter data taken over the Greenland ice sheet in 1991. The refurbished Advanced Application Flight Experiment (AAFE) airborne radar altimeter has a large range window and stores the entire return waveform during flight. Once the return waveforms are retracked, or post-processed to obtain the most accurate altitude measurement possible, they are compared with the highprecision Airborne Oceanographic Lidar (AOL) altimeter measurements.

The AAFE waveforms show evidence of varying degrees of both surface and volume scattering from different regions of the Greenland ice sheet. The AOL laser altimeter, however, obtains a return only from the surface of the ice sheet. Retracking altimeter waveforms with a surface scattering model results in a good correlation with the laser measurements in the wet and dry-snow zones, but in the percolation region of the ice sheet, the deviation between the two data sets is large due to the effects of subsurface and volume scattering. The Martin et al model results in a lower bias than the surface scattering model, but still shows an increase in the noise level in the percolation zone. Using an Ofiset Center of Gravity algorithm to retrack altimeter waveforms results in measurements that are only slightly affected by subsurface and volume scattering and, despite a higher bias, this algorithm works well in all regions of the ice sheet. A cubic spline provides retracked altitudes that agree with $A O L$ measurements over all regions of Greenland. This method is not sensitive to changes in the scattering mechanisms of the ice sheet and it has the lowest noise level and bias of all the retracking methods presented.
\end{abstract}

\section{INTRODUCTION}

$\mathbf{T}$ THE Advanced Application Flight Experiment (AAFE) radar altimeter was built by Hughes Aircraft company for NASA Wallops Flight Facility in 1974. At this time the Skylab S-193 radar altimeter had demonstrated its ability to make spaceborne altimetry measurements with a $10 \mathrm{nsec}$ transmitted pulse, and there was an increasing drive to achieve better range resolution. As a breadboard pulse compression radar, the AAFE radar altimeter accomplished this with a 1010:1 pulse compression ratio and an effective pulse width of 2.77 nsecs. The radar had many successful missions and demonstrated an altitude resolution of $2.1 \mathrm{~cm}$ over the ocean and a $10 \%$ sea wave height estimation accuracy [1]. One of the limitations

\footnotetext{
Manuscript received May 1994: revised February 1995. This work was supported in part by NASA under grant NGT-50606.

E. J. Ferraro is with the Radar Systems Laboratory, Raytheon Company, Wayland, MA 01778 USA.

C. T. Swift is with the Microwave Remote Sensing Laboratory, University of Massachusetts, Amherst, MA 01003 USA.

IEEE Log Number 9411242 .
}

of the AAFE radar altimeter, however, was that it had only 24 range bins, resulting in a 10 meter range window. This limited the tracking ability of the radar, causing it to lose lock over any rapidly changing surface. As a result, the radar was primarily used for oceanographic purposes.

In 1990, the AAFE altimeter was donated to the Microwave Remote Sensing Laboratory at the University of Massachusetts at Amherst. By this time, the analog/digital subsystem of the radar and its computer subsystem, which contained a teletype. a magnetic tape drive and a tape punch reader, had become obsolete, so the University of Massachusetts refurbished the entire radar system. This refurbishment converted the AAFE altimeter to a high resolution radar system with robust tracking ability and advanced computing, storage and data display capabilities. One of the major improvements was an increase in its range window size to $88 \mathrm{~m}$, enabling the radar to track over rapidly changing topographical surfaces such as glaciers, sea ice and land. Recent advances in digital technology allow the new system to digitize each retum waveform and store the entire result for post processing. Fig. 1 shows the amount of waveform processed and stored by the original AAFE system and by the refurbished radar. Since the refurbished system has a large range window and stores the entire retum waveform, the requirements of the AAFE on-board tracker are only to keep the waveform to within approximately 64 range bins (or $26 \mathrm{~m}$ ) of the center of the range window. In radar altimetry, tracking is the real-time process of keeping the entire return waveform in the range window during flight, while retracking is a post-processing method of obtaining the most accurate altitude measurement possible from the stored return waveform. Therefore, different retracking algorithms can produce varying altitude results and the accuracy and efficiency of the algorithms can be compared and analyzed.

In 1991, NASA conducted a multisensor airborne altimetry experiment over the Greenland ice sheet. This experiment was the first in a series of biennial experiments aimed at measuring small-scale changes in the topography and mass balance of the ice sheet, and at understanding the effects of penetration of a Ku-band radar altimeter pulse into the ice sheet. The AAFE Ku-band radar altimeter participated in this experiment along with the NASA Airborne Oceanographic Lidar (AOL), the NASA Airborne Terrain Laser Altimeter System (ATLAS) and the NASA Ka-band Surface Contour Radar (SCR). The experiment consisted of ten flights over the Greenland ice mass between Aug. 22 and Sept. 20, 1991 aboard the NASA 

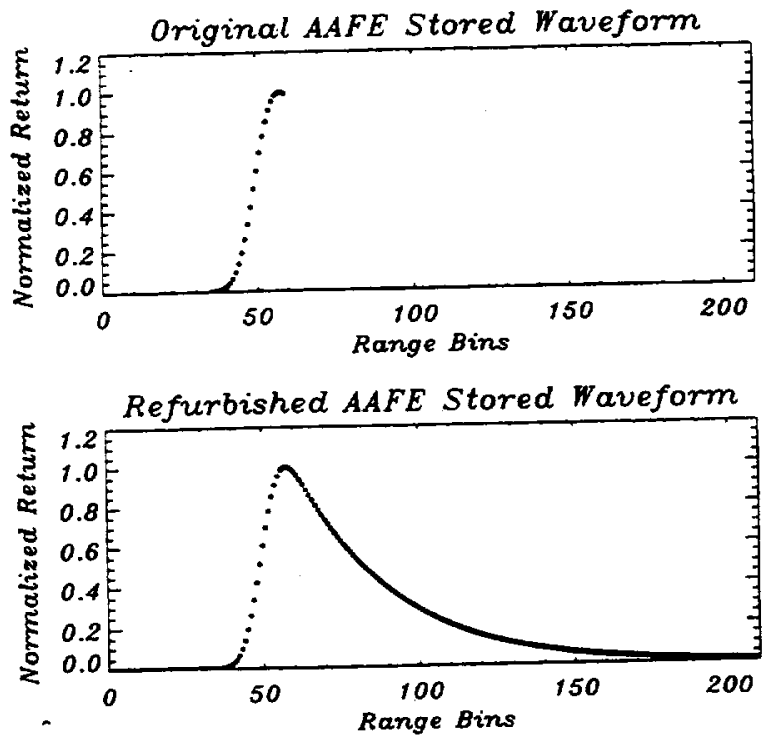

Fig. 1. Comparison of the original AAFE system waveform with only 24 range bins (top waveform) and the refurbished AAFE system waveform with over 200 range bins (bottom waveform).

P-3 aircraft. Positional information provided by three militarycode Global Positioning System (GPS) receivers aboard the NASA P-3 was used to control the autopilot of the aircraft. This system allowed accurate positioning under the European Remote Sensing satellite (ERS-1) trajectory and enabled accurate repeat missions on all flight lines. The missions were flown from Sondreström Air Force Base (now known as Kangerlussuaq) on the west coast of Greenland over the ice sheet at an average altitude of 400 meters above the surface and the flight lines covered an area between 65 and $75^{\circ} \mathrm{N}$.

All the remote sensing radar and laser instruments provided information about the aircraft altitude above the ice sheet. The GPS receivers, on the other hand, calculated the aircraft altitude above the ellipsoid, which is a reference around the surface of the earth. The difference between these two measurements is the actual ice sheet altitude above the ellipsoid.

\section{INSTRUMENT PERformanCE}

The Greenland ice sheet is divided into zones according to diagenetic facies, or physical and chemical characteristics, which were identified by Benson in 1962 [2]. The most common zones or stratigraphic regions are the ablation, soaked, percolation and dry-snow zones. In the ablation zone, which is usually near the edge of the ice sheet, the entire snowfall from the previous year is ablated or lost during the summer months. Similarly, in the soaked zone all the snow deposited over the previous year is raised to the melting point during the summer months, but it is not necessarily ablated. In this paper, the ablation and soaked regions will be referred to as the wetsnow zone. The percolation zone lies in the higher altitudes of the ice sheets, where there is less summer melting. Here the melt water percolates down through the upper layers of the ice sheet and freezes into ice layers, ice pipes and ice lenses. Finally, in the dry-snow zone melting never occurs.
The 1991 and 1993 experimental flights over Greenland passed over the wet-snow, percolation and dry-snow diagenetic zones of the ice sheet and, as the six representative waveforms in Fig. 2 show, the AAFE radar altimeter returns received from the various zones differed significantly in shape. Each of the waveforms in Fig. 2 is normalized in power with a single range bin equivalent to $2.77 \mathrm{~ns}$ or $41.67 \mathrm{~cm}$ and the latitude and longitude where each waveform was received along with the ice altitude above the ellipsoid at that point are noted. These variations in the waveform shape are due to differences in the scattering properties of the various zones of the ice sheet. Fig. 3 shows the boundaries of the diagenetic zones in Greenland as well as the location on the ice sheet where each waveform was obtained. Waveforms 1 and 2 , which have a large slope or sharp leading edge and a sharp trailing edge, come from the wet-snow zone. The trailing edges on waveforms 3 and 4 , which are from the percolation zone, have a smaller slope than waveforms 1 and 2 , while the leading edges remain sharp. Waveforms 5 and 6 , which were obtained near the summit in the dry snow zone, still have a sharp leading edge, but the trailing edge is long and gently sloping. As these waveforms show, the different surface and subsurface scattering properties in each of the diagenetic zones affects the AAFE retum waveform. Since many retracking algorithms use the entire waveform to determine the instrument altitude, it is important to know which algorithms will be affected by the changing waveform shape over the different zones and which ones will produce poor altitude results due to subsurface and volume scattering. A good retracking algorithm will provide accurate results despite the changing radar altimeter waveform shape.

By comparing AAFE altitude results with independent ground truth measurements, the system biases and noise levels of the instrument have been determined. In the 1991 Greenland experiment, a ground survey was conducted on the Sondreström runway with a GPS receiver mounted on a truck. Since the truck could move slowly down the runway, each GPS three dimensional measurement was averaged for several seconds. Comparisons to traditional survey results and between data sets on different days, reveal that these runway ground truth data have a maximum bias of $1 \mathrm{~cm}$ and a maximum noise level of $3 \mathrm{~cm}$.

Each radar return waveform from the smooth runway surface represents the flat-surface response of the instrument. Since scattering from a flat surface is well understood, the resulting retracked AAFE runway measurements are extremely accurate and can be used to remove overall system biases. When the aircraft flew over the runway, the AAFE altimeter was able to take one hundred and fifty altitude measurements spaced approximately ten meters apart. The GPS ground truth data set has many more samples, therefore all the ground-based measurements that fall within a single pulse-limited footprint of the altimeter are averaged together before being compared to the retracked AAFE altitude. Fig. 4(a) shows a comparison between the AAFE altimeter results from Sept. 18, 1991 and ground-based GPS measurements from Sept. 10, 1991. Since the two data sets agree well, the best way to determine the system bias and noise level is to analyze the difference between 

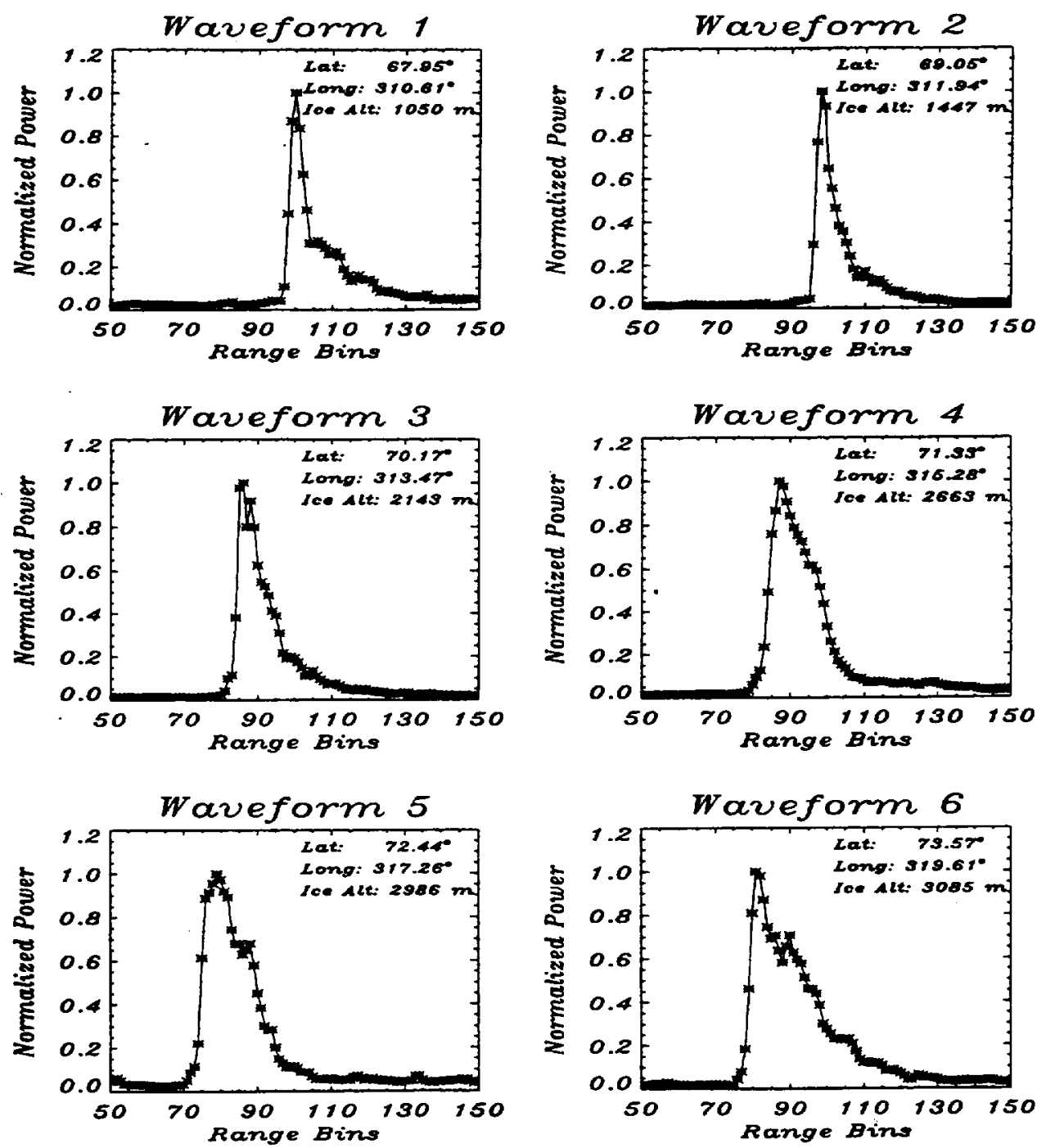

Fig. 2. Six altimeter return waveforms from the Greenland ice sheet during a September 1991 mission. Waveforms 1 and 2 were obtained from the wet-snow zone, waveforms 3 and 4 from the percolation zone, and waveforms 5 and 6 from the dry-snow zone.

them. The plot of the AAFE altitude minus the ground GPS altitude in Fig. 4(b) shows that the mean altitude difference is $-8 \mathrm{~cm}$ and the noise level of the difference is $12 \mathrm{~cm}$. Similar comparisons for runway passes on other flight days reveal that the mean difference remains between -6 and $-8 \mathrm{~cm}$ and the noise level stays between 12 and $14 \mathrm{~cm}$. Thus, the maximum rms precision of the altitude measurements for the Greenland experiments, including all instrumental and aircraft errors, is approximately $14 \mathrm{~cm}$.

The NASA Airbome Oceanographic Lidar (AOL) is a $523 \mathrm{~nm}$ wavelength scanning laser altimeter. Since the AOL has centimeter altitude precision and its short-wavelength prevents it from penetrating into glacial ice, AAFE altimeter measurements have been compared to the AOL to determine accuracy, to study the effects of penetration of the $\mathrm{Ku}$-band AAFE pulse into the ice and to evaluate retracking algorithms. Knowing which retracking methods have the smallest bias and the lowest noise level over all the diagenetic zones will help remove possible biases in satellite radar altimetry over the Greenland and Antarctic ice sheets.

\section{COMPARISON OF RETRACKING ALgORTTHMS}

As Fig. 1 shows, the entire AAFE return waveform is completely stored during flight so that it can be processed at a later time. The reason for post-processing is to retrack the stored return or find the exact point on the waveform that corresponds to the mean surface. There are several different ways to retrack a return waveform, such as fitting to a scattering model or using a mathematical algorithm. Although retracking ocean return waveforms is well understood, returns from more complex surfaces such as ice sheets are not as predictable due to the different diagenetic zones and therefore they are much more difficult to retrack. Since the AOL laser altimeter receives a return only from the surface and does not penetrate into the ice sheet, its altitude measurements can be compared with AAFE altimeter retracked altitudes and the results used to analyze retracking methods.

There is always a surface scattering component in the AAFE retums from the Greenland ice sheet even in the percolation and dry-snow zones [3], [4] and therefore, one method of 


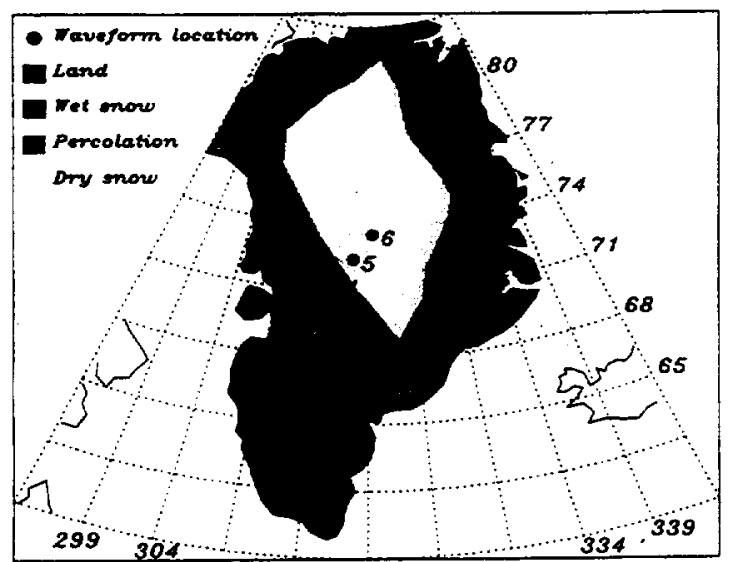

Fig. 3. Distribution of the diagenetic zones in Greenland according to Benson and the location of the six altimeter waveforms of Fig. 2.

retracking the waveforms is to fit them to a surface scattering model. Surface scattering from a randomly distributed rough surface has been described by [5] as the convolution of the flat surface impulse response with the distribution of height scatterers. The flat surface impulse response, $P_{f s}(t)$, is calculated by assuming a transmitted impulse and using the radar range equation

$$
P_{f s}(t)=\frac{P_{t} \lambda^{2}}{(4 \pi)^{3}} \int_{\text {illum area }} \frac{\delta\left(t-\frac{2 R}{c}\right) G^{2}(\theta) \sigma^{\circ}(\theta)}{R^{4}} d A
$$

where the gain of the radar antenna is approximated as

$$
G(\theta)=G_{0} e^{-4 \ln 2 \theta^{2} / \theta_{B}^{2}}
$$

[6]. The backscatter coefficient for the surface is

$$
\sigma^{\circ}(\theta)=\frac{\Gamma\left(0^{\circ}\right)}{s^{2} \cos ^{4} \theta} e^{-\tan ^{2} \theta / s^{2}}
$$

[7] where $\Gamma\left(0^{\circ}\right)$ is the power reflection coefficient at nadir and $s$ is the rms surface slope. For small incidence angles, it can be approximated by

$$
\sigma^{\circ}(\theta)=\frac{\Gamma\left(0^{\circ}\right)}{s^{2}} e^{-\theta^{2} / s^{2}}
$$

Convolving $P_{f s}(t)$ with a Gaussian height distribution of scatterers with a standard deviation of $\sigma_{h}$ leads to a rough surface impulse response of

$$
P_{r s}(\tau)=\frac{C_{0}}{H^{3} s^{2}} e^{\left(t_{p} / t_{s}\right)^{2}} e^{-\left(2 \tau / t_{s}\right)} \operatorname{erfc}\left(\frac{t_{p}}{t_{s}}-\frac{\tau}{t_{p}}\right)
$$

where

$$
\begin{aligned}
C_{0} & =\frac{P_{t} \lambda^{2} G_{o}^{2} \Gamma\left(0^{\circ}\right)}{32 \pi^{2}}, \\
\tau & =t-\frac{2 H}{c}, \\
t_{p} & =\frac{2 \sqrt{2} \sigma_{h}}{c}, \\
t_{s} & =\frac{2 H}{c} \frac{1}{\frac{8 \ln 2}{\theta_{B}^{2}}+\frac{1}{s^{2}}}
\end{aligned}
$$

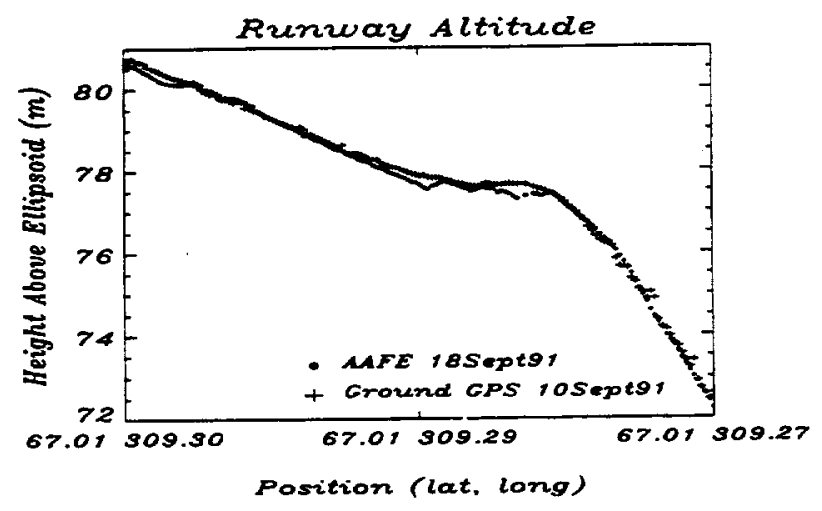

(a)

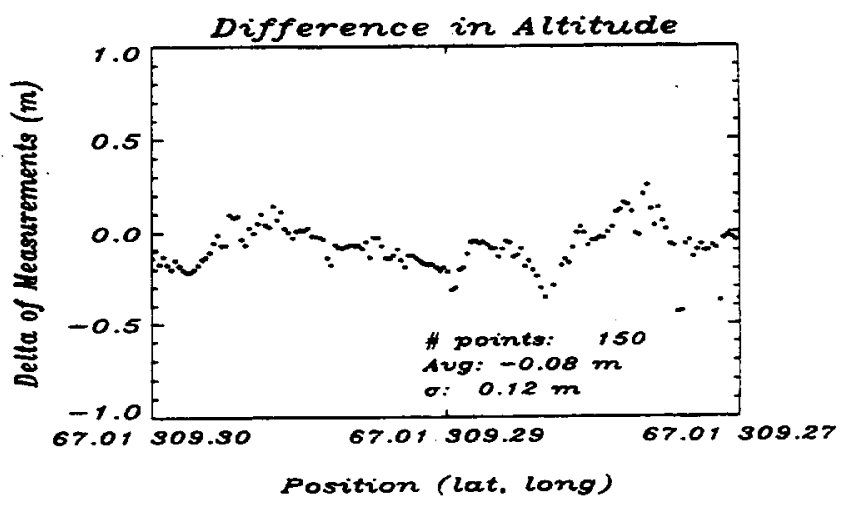

(b)

Fig. 4. A comparison between the AAFE altimeter altitude measurements on Sept. 18, 1991 and the ground-based GPS altitude measurements on Sept. 10, 1991. (a) The actual AAFE and ground GPS altitude measurements and (b) the difference between the two data sets calculated by subtracting the ground GPS altitude measurements from the AAFE altitude measurements.

and erfe is the complementary error function [5], [6]. The total rough surface system response is then calculated by convolving the rough surface impulse response with the system point target response, which can be approximated as a Gaussian pulse with a $3 \mathrm{~dB}$ width of $\tau_{p}$ and a standard deviation of $\sigma_{p}=.425 \tau_{p}$ [5]. The result is the same as (5), except $t_{p}$ is now defined as

$$
t_{p}=\sqrt{2} \sqrt{\left(\frac{2 \sigma_{h}}{c}\right)^{2}+\sigma_{p}^{2}}
$$

To determine the range to the surface, $\mathrm{H}$, AAFE return waveforms are fit using the least-mean-squared error (LMSE) method [8], [9] to a nonlinear five-parameter model, which is (5) plus a parameter, $a$, representing the noise floor of the waveform, or

$$
P_{r s(\text { fit })}(\tau)=a+\frac{C_{0}}{H^{3} s^{2}} e^{\left(t_{p} / t_{s}\right)^{2}} e^{-\left(2 \tau / t_{s}\right)} \operatorname{erfc}\left(\frac{t_{p}}{t_{s}}-\frac{\tau}{t_{p}}\right) \text {. }
$$

The five parameters in this model are $H, \sigma_{h}, s, C_{0}$ and $a$.

Fig. 5 shows the resulting AAFE retracked altitudes using the surface scattering model and the AOL altitude measurements taken over a south-west to north-east flight line. The inset in the figure illustrates the location of the transect on the Greenland map. This figure also shows the approximate 


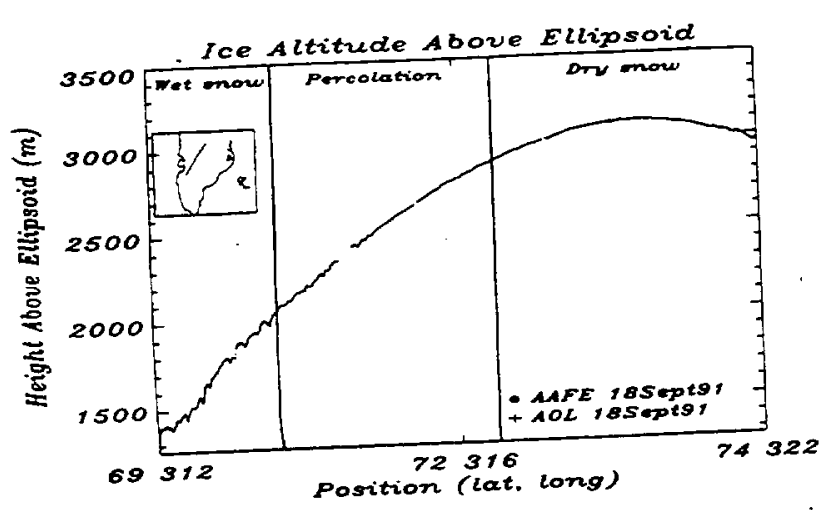

Fig 5. AAFE altitude measurements retracked using the surface scattering E altide measurement. model along with the corresponding AOL altitude measurements fort ice sheet 18,1991 fight from the south-wes
(see inset for map of transect).

transitions of the diagenetic zones of the Greenland ice sheet according to [2]. The break in the data at $70.54,314.00$ is due to missing AOL data caused by the laser losing lock on ice fog above the surface of the ice sheet. Since the ice sheet altitude changes from 1200 meters to over 3000 meters over the flight line, the scale makes it impossible to distinguish between the two sets of measurements. Fig. 6(a) shows the difference between the AAFE and AOL altitudes over the section and also displays the average difference and standard deviation, which are -28 and $30 \mathrm{~cm}$ respectively. The spikes on the left side of the difference plot are the result of large instrumental mispointing angles due to aircraft maneuvering. In general, the two data sets agree well in the wet-snow and dry-snow zones, but deviate significantly in the percolation zone. This increase in the percolation zone is due to the effects of volume scattering from the subsurface ice layers, pipes and lenses. Waveforms 3 and 4 in Fig. 2 were obtained in the percolation zone and illustrate the contribution of these subsurface ice features, such as the secondary peaks and a trailing edge that is non-exponential. Combined surface and volume scattering models are often used for measuring geophysical parameters of the ice sheet as described in [3], [10] and they work well in the wet and dry-snow zones. The percolation zone, however, is difficult to model and the density and distribution of the ice features in this region varies significantly. Therefore, retracking by fitting to the surface scattering model described above or to a combined surface and volume scattering model is not recommended for altimeter returns from the percolation zone.

Another method of retracking is to fit the waveforms to a five parameter continental ice sheet retracking algorithm developed in [11]. This model is a modification to Brown's surface scattering model. Instead of an exponential trailing edge this model has a linear trailing edge and is defined as

$$
\operatorname{Pr}(\tau)=\beta_{1}+\beta_{2}\left(1+\beta_{5} Q(\tau)\right) P\left(\frac{\tau-\beta_{3}}{\beta_{4}}\right)
$$

where $Q(\tau)$ and $P(z)$ are

$$
Q(\tau)= \begin{cases}0 & \tau<\beta_{3}+0.5 \beta_{4} \\ \tau-\beta_{3}+0.5 \beta_{4} . & \tau \geq \beta_{3}+0.5 \beta_{4}\end{cases}
$$

$$
P(z)=\frac{1}{\sqrt{2 \pi}} \int_{-\infty}^{z} e^{-q^{2} / 2} d q=\frac{1}{2}+\frac{1}{2} \operatorname{erf}\left(\frac{z}{\sqrt{2}}\right)
$$

[12]. In this model, $\beta_{1}$ is the noise floor parameter, $\beta_{2}$ represents the amplitude, $\beta_{3}$ is the range or height to the mean surface, $\beta_{4}$ is the waveform rise time and $\beta_{5}$ is the slope of the trailing edge. Reference [11] also defines a model for double ramped waveforms, which are often found in SEASAT altimeter returns, but this will not be presented here because double ramps are not found in the AAFE airborne altimeter waveforms.

Fig. 6(b) shows the difference between AAFE altitudes retracked with the Martin model and the corresponding AOL altitude measurements. The average difference between the two data sets is $-18 \mathrm{~cm}$ and the standard deviation is 26 $\mathrm{cm}$. This is the same flight line shown in Fig. 5 and it appears that the surface scattering and Martin models produce similar results in the wet-snow and dry-snow regions. In the percolation zone, however, the noise of the Martin model is reduced, but there is still an increase in the difference level showing that this retracking algorithm is sensitive to subsurface and volume scattering.

The third retracker is the Offset Center of Gravity (OCOG) algorithm, which is a tracking method developed by the Mullard Space Science Laboratory that uses an estimate of the pulse width to track the return waveform. The width of the pulse, $W$, is approximated using

$$
W=\frac{\left(\sum_{n=0}^{k-1} p_{n}\right)^{2}}{\sum_{n=0}^{k-1} p_{n}^{2}}
$$

where $k$ is the total number of range bins and $p_{n}$ is the power in range bin $n$. Since the waveform is stored as an array, $p_{n}$ is the value of the $n$th element of the array. For example, a pulse defined as

$$
p_{n}= \begin{cases}A & m \leq n<m+j \\ 0 & \text { otherwise }\end{cases}
$$

results in $W=j$. The OCOG tracker then calculates the center of area of the pulse as

$$
\frac{\sum_{n=0}^{k-1} n p_{n}}{\sum_{n=0}^{k-1} p_{n}}-\frac{W}{2}
$$

[13] and uses the result as the rack bin.

The difference between the AAFE altitude measurements retracked with the OCOG algorithm and the corresponding AOL altitude measurements are shown in Fig. 6(c). This comparison yields a $-50 \mathrm{~cm}$ average bias and a noise level of $32 \mathrm{~cm}$. Although, this is higher than the surface scattering or Martin models, the noise level across the flight line only increases slightly in the percolation zone. This means that the OCOG retracking algorithm is not as sensitive to the change in altimeter waveform shape due to the different zones and 


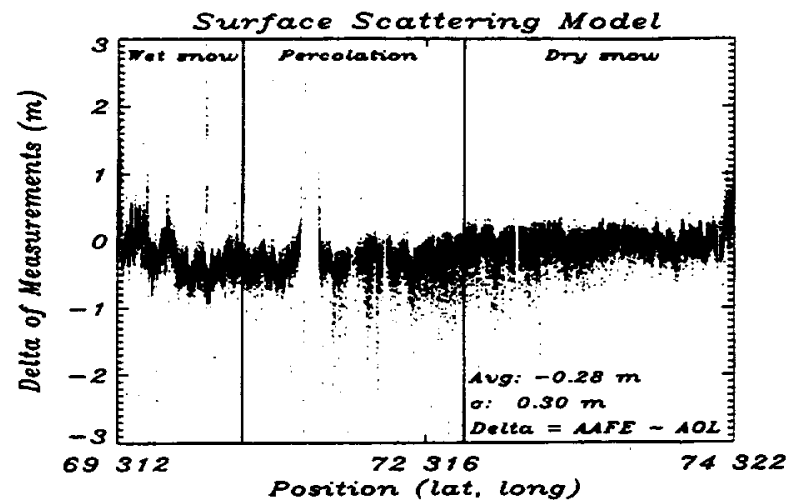

(a)

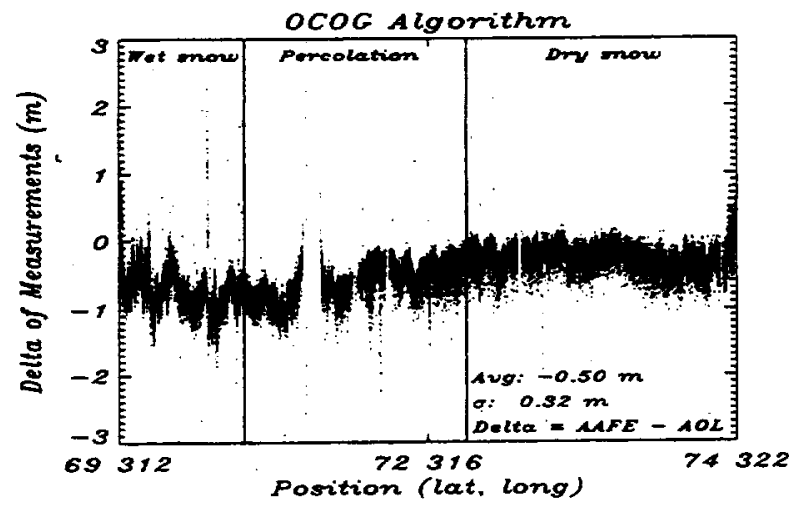

(c)

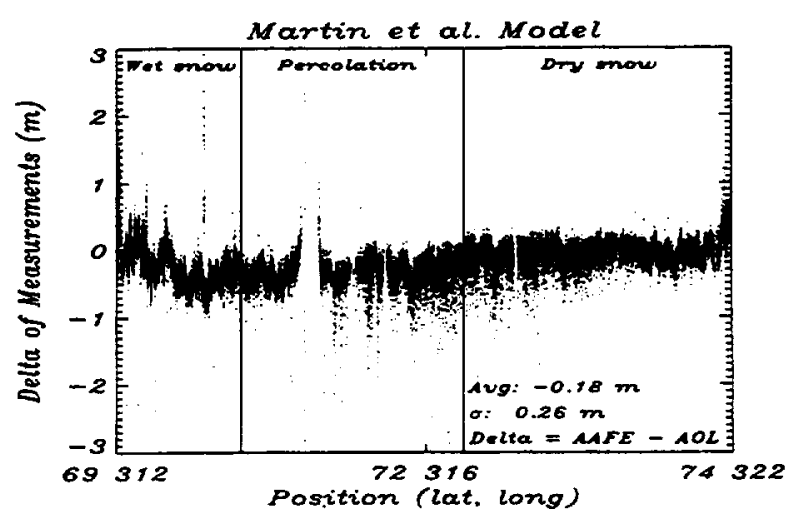

(b)

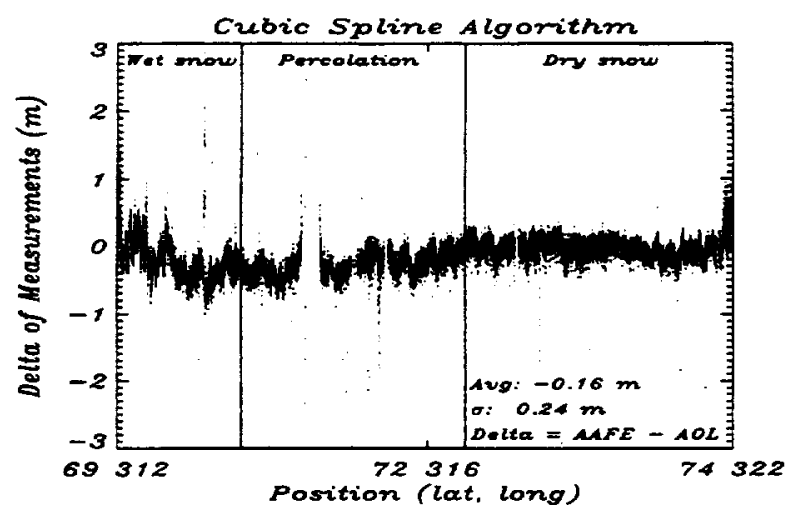

(d)

Fig. 6. The difference between AAFE and AOL altitude measurements over the south-west to north-east pass shown in Fig. 5, where the AAFE waveforms were retracked (a) by fitting to a surface scattering model, (b) by fitting to the Martin model, (c) using the Offset Center of Gravity and (d) using a cubic spline algorithm. The difference was calculated by subtracting the AOL measurements from the AAFE retracked results and there are more than 65000 parts in each plot difference.

therefore is a good method of retracking over all sections of the Greenland ice sheet.

Another method of retracking is to use a cubic spline [9] to find the point on the waveform that corresponds to the mean surface. This mathematical algorithm interpolates between the sampled data and returns a curve that passes through all points. The object of the cubic spline interpolation is to produce a function that is continuous in both the first and second derivative [14]. Since this algorithm is well documented [9], [14] and many analysis programs have it as a standard procedure, the equations and detailed explanation of the cubic spline will not be presented here. When a cubic spline is performed on an AAFE return waveform, the result is a smooth curve representing all original sampled data points. As the waveforms in Fig. 2 show, the airborne altimeter returns always have a sharp leading edge. The curve produced by the spline models the leading edge of the waveform well and is used to determine the half power point corresponding to the mean surface. Fig. 6(d) shows the difference between AAFE altitude measurements retracked using the cubic spline and the corresponding AOL altitudes. The mean difference of $-16 \mathrm{~cm}$ and standard deviation of $24 \mathrm{~cm}$ reveals that the cubic spline retracking method has the lowest noise level over the entire flight line and as Fig. 6(d) shows it is unaffected by the change in the waveform shape in the percolation zone.

\section{DISCUSSION AND CONCLUDING REMARKS}

The AAFE radar altimeter returns have varying degrees of surface, subsurface and volume scattering from the different regions of the Greenland ice sheet. If the amount of each type of scattering is known, then models such as the surface scattering model presented in this paper and the Martin model would probably work better than shown in Fig. 6(a) and (b). Unfortunately, it is difficult to have this apriori knowledge of the ice sheet conditions and the varying subsurface conditions in the percolation zone make it even more difficult to model. Ground truth measurements taken with a $\mathrm{Ku}$-band groundbased radar in the percolation zone during a 1993 Greenland experiment show, however, that there is always a surface return from the ice sheet [15], [16]. Similarly, analysis of AAFE waveforms reveal that the leading edge of the waveform is due to a return from the air-snow interface at the ice sheet surface.

This explains the performance of the cubic spline retracking method which uses the resulting spline of the leading edge to determine the altitude. In addition, this retracking algorithm is not susceptible to changes in the trailing edge because it does not attempt to model the shape of the waveform. Similarly, the Offset Center of Gravity does not fit to a model like the surface and Martin models. Since the entire return pulse must be included in the calculation of the center of gravity, the 
changes in the waveform trailing edge in the percolation zone do have some affect on the results of the algorithm.

Since both satellite and airborne radar altimetry over ice sheets require a large number of waveforms to be retracked, it is also important to compare the computational times of retracking methods. The OCOG algorithm takes 0.5 hours to retrack one flight hour of AAFE data, while the cubic spline takes 8 hours and both the surface scattering and the Martin models take approximately 30 hours. Although these measurements were made on a single computer system, they give a relative comparison of computational times. Therefore, to obtain quick first order retracked AAFE altitude measurements, the OCOG retracking algorithm is the most efficient, but the cubic spline is the better method for obtaining accurate range measurements over all the diagenetic regions of the ice sheet.

Many scientists and researchers who work with satellite radar altimetry may find that the airborne waveforms shown in Fig. 2 look very different from spaceborne altimeter return waveforms. Therefore, it is important to include a discussion on the causes of the differences. One reason is the significantly smaller footprint of the airborne instrument. The AAFE altimeter has a $15.6^{\circ} 3 \mathrm{~dB}$ beamwidth and a 2.77 ns compressed pulse width and, as a result, when the aircraft altitude is 400 meters, its pulse-limited footprint is less than 20 meters and its beam-limited footprint is less than 125 meters. A reflective surface that is rough enough to reflect power back to the radar even at the farthest extent of the beam-limited footprint will create an AAFE waveform that is approximately 30-40 range bins wide from the beginning of the leading edge to the end of the trailing edge. The SEASAT satellite radar altimeter had a similar pulse width of 3.2 nsecs, but its $1.6^{\circ}$ beamwidth and $800 \mathrm{~km}$ orbit [17] result in pulse-limited and beam-limited footprint radii of greater than $875 \mathrm{~m}$ and $22 \mathrm{~km}$, respectively. As a result, SEASAT returns from the same rough surface will create waveforms that are more than 100 range bins wide. The range bin size of both systems is equivalent due to the similar pulse widths, but this significant difference in the waveform width or length of the trailing edge makes the two returns appear very different.

Another cause for the differences between the airborne and satellite waveform shapes is the effects of RMS surface slope, $s$, on the altimeter waveform. Fig. 7(a) shows the effects of varying $s$ on the AAFE retum waveform for a constant altitude of 400 meters. Once the RMS surface slope approaches the same order of magnitude as the AAFE beamwidth, the waveform achieves its maximum width or the return is a full waveform. RMS surface slope values on the order of $15.6^{\circ}$, however, are very unlikely and therefore surface scattering alone can not produce a full waveform for the AAFE altimeter. As Fig. 7(b) shows, the SEASAT returns approach a maximum width or a full waveform when the RMS surface slope exceeds $1.6^{\circ}$. Since the RMS surface slope on the Greenland ice sheet is usually less than a few degrees, the effects of volume scattering on the trailing edge of the AAFE waveform are easy to see. The SEASAT satellite altimeter returns, on the other hand, are typically full waveforms and the effects of volume scattering on the trailing edge are less evident.

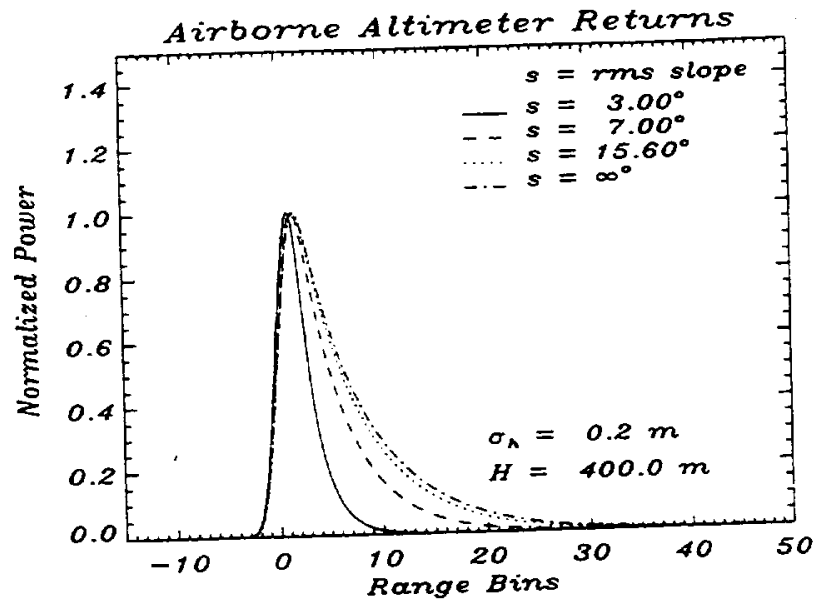

(a)

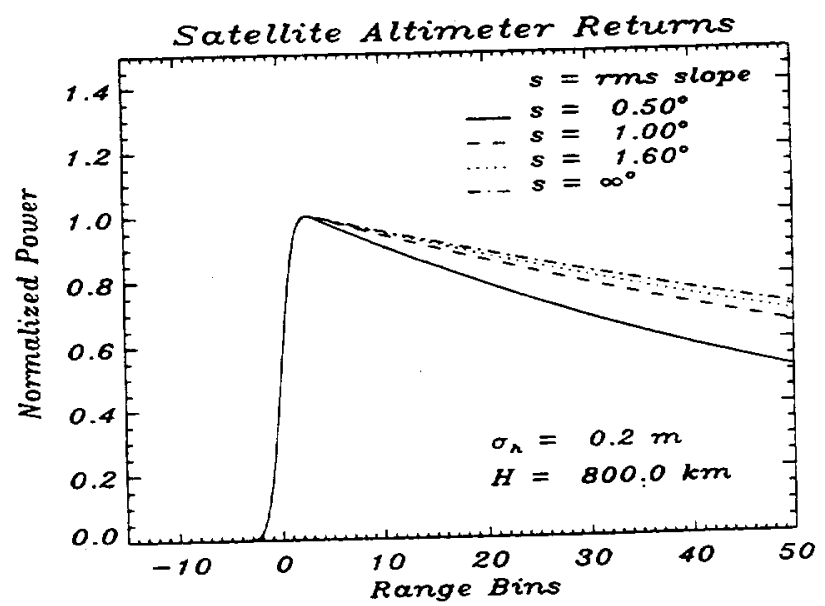

(b)

Fig. 7. Comparison of airbome and satellite altimeter waveforms. (a) Effects of varying RMS surface slope on the airborne AAFE altimeter return wave等 form (assuming a constant altitude of 400 meform (assuming a constant altitude of $800 \mathrm{~km}$ and a beamwidth of $1.6^{\circ}$ )

Despite these differences in the airborne and satellite waveforms, the information provided by comparing the airborne AAFE results with the AOL measurements allows ice sheet retracking methods to be analyzed and new retracking methods to be developed. In order to simulate satellite return waveforms during future missions over the Greenland ice sheet, a smaller beamwidth antenna will be used and the aircraft will fly some flight lines at much higher altitudes to keep the instrument operating in the pulse-limited mode. These comparisons will allow an even better understanding and assessment of retracking methods used for satellite radar altimetry over the Greenland ice sheet.

\section{ACKNOWLEDGMENT}

The authors would like to thank the Observational Sciences Branch at the NASA Wallops Flight Facility, especially B. Krabill and E. Frederick for providing the GPS and AOL data. They would also like to thank Dr. R. Thomas for providing the funding for this project. 


\section{REFERENCES}

[1] NASA, Final Report of the Advanced Application Flight Experiment Breadboard Pulse Compression Radar Altimeter Program, NASA Contractor Rep. CR-141411, 1976.

[2] C.S. Benson, "Stratigraphic studies in the snow and fim of the greenland ice sheet," Research Rep. 70, U.S. Army Snow Ice and Permafrost Research Establishment, 1962.

[3] E. J. Ferraro and C. T. Swift, "Using airborne radar altimetry renums to model the diagenetic zones of greenland and measure geophysical parameters of the ice sheet," submitted to J. Glaciology, 1994.

[4] C. H. Davis and R. K. Moore, "A combined surface and volume scattering model for ice sheet radar altimetry," J. Glaciology, vol. 39, no. $133,1993$.

[5] G. S. Brown, "The average impulse response of a rough surface and its applications," IEEE J. Oceanic Eng., vol. OE-2, no. 1, pp. 67-74, 1977.

[6] D. E. Barrick, Remote Sensing of the Troposphere. Washington, DC: U.S. Government Printing Office, 1972, ch. 12.

17] F. C Jackson. W. T. Walton, D. E. Hines, B. A. Walter, and C. Y Peng, "Sea surface mean surface slope from ku-band backscatter data," J. Geophys. Res., vol. 97, no. C7, pp. 11411-11427, 1992.

[8] B. Camahan, H. A. Luther, and J. O. Wilkes, Applied Numerical Methods. New York: Wiley, 1969.

[9] W. H. Press, B. P. Flannery, S. A. Teukolsky, and W. T. Verterling. Numerical Recipes in C. Cambridge, UK: Cambridge University Press, 1988.

[10] C. H. Davis and H. J. Zwally, "Geographic and seasonal variations in the surface properties of the ice sheets by satellite radar altimetry," $J$. Glaciology, vol. 39, no. 133, 1993.

[11] T. V. Martin, H. J. Zwally, A. C. Brenner, and R. A. Bindschadler, "Analysis and retracking of continental ice sheet radar altimeter waveforms," J. Geophys. Res., vol. 88, no. C3, pp. 1608-1616, 1983

[12] H. J. Zwally, A. C. Brenner. J. A. Major, T. V. Martin, and R. A. Bindschadler. "Satellite radar altimetry over ice, volume 1-Processing and corrections of seasat data over greenland," NASA, Ref. Pub. 1233,

1990.
[13] D. J. Wingham, C. G. Rapley, and H. Griffiths, "New techniques in satellite altimeter tracking systems," in Proc. IGARSS 1986 Symp., 1986, pp. 1139-1344.

[14] J. Ahlberg. E. Nilson, and J. Walsh. The Theory of Splines and Their Applications. New York: Academic Press, 1967.

[15] 1. H. Zabel. P. A. Baggeroer, and K. C. Jezek, "Radar and snow studies in the percolation zone of the greenland ice sheet: A data report on the 1993 field season at dye 2," Tech. Note 94-01, Byrd Polar Research Center, 1994.

[16] I. Zabel, Byrd Polar Research Center, 1993, personal communicarion.

[17] C. H. Davis, "Satellite radar altimetry," IEEE Trans. Microwave Theory Tech, vol. 40, no. 6, pp. 1070-1076. 1992.

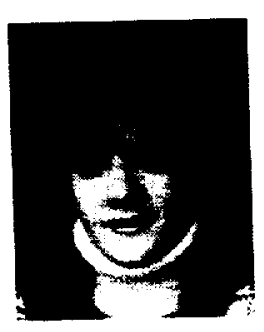

Ellen J. Ferraro (S'89-M'95) received the B.S.E.E. and Ph.D. degrees in electrical and computer engineering from the University of Massachusetts, Amherst, in 1989 and 1994 , respectively.

In July 1994, she joined the Radar Systems Laboratory at Raytheon Company, where she is involved in the analysis of ocean scattering and propagation over the ocean for Vessel Traffic Control radar systems and in the development of spread clutter mitigation techniques for enhanced small target detection with HF Over the Horizon Radars.

Dr. Ferraro is an officer in the Boston Section of the Society of Women Engineers.

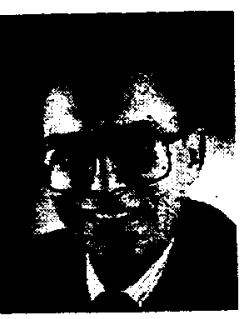

Calvin T. Swift (M'67-SM'69-F'83) was born in Prince William County, Virginia. He received the S.B. degree from Massachusetts Institute of Technology, Cambridge, the M.S. degree from Virginia Polytechnic Institute, Blacksburg, and the Ph.D. degree from the College of William and Mary, Williamsburg, VA, in 1959, 1965, and 1969, respectively.

He was employed as a Research Engineer by North American Aviation (now Rockwell International), Downey, CA from 1959 to 1962 , where he worked on a variety of defense and space-related problems. In 1962. he joined the NASA Langley Research Center, Hampton, VA, where he initially conducted research on plasma-covered antennas. After 1970, he was involved in microwave remote sensing of the Earth; and assumed leadership responsibility of a microwave radiometer group at Langley. Since 1981, responsibility of a microwave radical and Computer Engineering. University of Massachusetts. Amherst, and is Co-Director of the Microwave Sensing Laboratory. He has published numerous articles and book chapters in the areas of antennas, wave propagation, plasmas, and microwave remote sensing.

Professor Swift was elected vice-chairman and later chairman of U.S. Professor Swift was end Non-Ionized Media) of the international Union of Radio Science (URSI). He served the IEEE Antennas and Propagation Society as Technical Program Chairman of the International AP-S/URSI Society as Technical Program Chairman of the international AP-STURS Symposium, Willamsburg, VA in (AdCom); serving as Meetings Chairman. the AP-S Administrative Committee (AdCom), ser Chaiman of Long Range Planning. He was twice elected to the Administrative Committee of the IEEE Geoscience and Remote Sensing Society and was president of the Society in Geoscience and Remote Sensing Sor many journals and was Guest Editor for the AP-S/JOE (Joumal of Oceanic Engineering) special joint issue on Radio Oceanography. He is a past Editor of the Transactions ON GEOSCIENCE AND REMOTE SENSTNG and a former Associate Editor of JOE. In 1984, he was awarded a centennial medal from the IEEE. He was also awarded the IEEE Geoscience and Remote Sensing Distinguished Achievement Award in 1994. 